\title{
Two new genera of Laophontidae (Copepoda: Harpacticoida) without sexual dimorphism in the endopods of the swimming legs
}

\author{
HENDRIK GHEERARDYN ${ }^{1}$, FRANK FIERS ${ }^{2}$, MAGDA VINCX ${ }^{1} \&$ MARLEEN DE TROCH ${ }^{1}$ \\ ${ }^{\prime}$ Marine Biology Section,Biology Department, Ghent University, Campus Sterre - Building S8, Krijgslaan 281, \\ B-9000 Ghent, Belgium. E-mail: hendrik.gheerardyn@ugent.be \\ ${ }^{2}$ Royal Belgian Institute of Natural Sciences, Section of Recent Invertebrates, Vautierstraat 29, B-1000 \\ Brussels, Belgium
}

\begin{abstract}
Two new monospecific genera of the harpacticoid family Laophontidae T. Scott, 1905 are described here. Apistophonte wasiniensis gen. et sp. n. was found along the Kenyan coast and Propephonte duangitensis gen. et sp. n. along the northern coast of Papua New Guinea. They differ from most other laophontid genera in the absence of sexual dimorphism in the endopods of the swimming legs. At first sight, both new species resemble each other very closely in habitus, integumental ornamentation, chaetotaxy of the swimming legs and absence of sexual dimorphism in the endopods. However, the detailed characteristics of A1, maxilla and male P5 show that the species are not congeneric.

The structure of the first antennular segment of Propephonte gen. n. suggests a close relationship with Peltidiphonte Gheerardyn and Fiers, 2006. The exact affinities of Apistophonte gen. n. however remain difficult to assess.
\end{abstract}

Key words: Harpacticoida, Laophontidae, Propephonte gen. n., Apistophonte gen. n.

\section{Introduction}

Along the eastern coasts of Kenya and Zanzibar (Tanzania), harpacticoid copepod communities associated with dead coral substrates are being studied. As such, different types of substrate, ranging from coral sand, fine coral gravel and coral rubble to large coral fragments, have been sampled. Until now, the qualitative samples from the Kenyan coast yielded 44 species of the family Laophontidae T. Scott, 1905, including 28 which are new to science (four species have been described so far (Gheerardyn et al. 2006; Gheerardyn et al. in press)).

In this paper we describe one of the new Kenyan species, which is mainly 
characterised by the absence of sexual dimorphism in the endopods of the swimming legs.

As this species cannot be attributed to any of the known laophontid genera, a new genus is established.

In the course of a thorough revision of the Laophontidae by Fiers (1988), numerous samples were studied from different substrates and various locations in the Atlantic, Indian and Pacific Ocean. Along the northern coast of Papua New Guinea, a coral sand and rubble sample contained a new laophontid species, which also lacks sexual dimorphism in the endopods of the swimming legs. Although this species closely resembles the formerly mentioned new Kenyan species, it is attributed to another new genus based on the detailed characteristics of the antennule, maxilla and male P5. The possible relationships of these two new genera with the other laophontid genera is discussed herein.

\section{Material and methods}

Along the eastern coast of Kenya, meiofauna samples were collected from various dead coral substrates (ranging from coral sand, fine coral gravel and coral rubble to large coral fragments). Prior to fixation, epifauna from coral fragments and coral rubble were rinsed off with filtered seawater over a $1 \mathrm{~mm}$ and a $32 \mu \mathrm{m}$ sieve. Samples from coral gravel were obtained by decanting the coral gravel (ten times) over a $32 \mu \mathrm{m}$ sieve. Buffered formaldehyde was added to a final concentration of $4 \%$. In the laboratory, samples were centrifuged three times with Ludox HS40 (specific density 1.18) and finally stained with Rose Bengal.

Along the northern coast of Papua New Guinea, several samples of coral sand and coral rubble were collected following a slightly different procedure. Buffered formaldehyde (final concentration 4\%) was added immediately to to the sampled substrates. In the laboratory, samples were rinsed with a jet of freshwater over a $5 \mathrm{~mm}$ and a $45 \mu \mathrm{m}$ sieve, and centrifuged three times with Ludox HS40 (specific density 1.18).

Harpacticoid copepods were sorted out and counted using a Wild M5 binocular microscope and were stored in $75 \%$ ethanol. Dissected parts of the specimens were mounted in glycerine. Preparations were sealed with insulating varnish. Observations and drawings were made on a light microscope (Leica DM LS) equipped with a drawing tube. In toto specimens are stored in $75 \%$ neutralised ethanol. Type specimens have been deposited in the Invertebrate Collections of the Royal Belgian Institute of Natural Sciences (KBIN) (Brussels, labelled COP). Scale bars in figures are indicated in $\mu \mathrm{m}$.

The descriptive terminology of Huys et al. (1996) is adopted. Abbreviations used in the text are: A1, antennule; A2, antenna; ae, aesthetasc; exp, exopod; enp, endopod; P1-P6, first to sixth thoracopod; exp(enp)-1(2,3) to denote the proximal (middle, distal) segment of a ramus. 
Family Laophontidae T. Scott, 1905

Subfamily Laophontinae T. Scott, 1905 sensu Huys and Lee, 2000

\section{Genus Apistophonte Gheerardyn and Fiers gen. n.}

Diagnosis. Laophontidae. Body fusiform prehensile. Rostrum prominent. Integument of cephalothorax and somites pitted. Posterodorsal margin of prosomites, urosomites and anal operculum serrate. Ventral surface of third male urosomite with several short rows of long spinules. Caudal rami cylindrical without dorsal processes. Female antennule 6segmented; first segment short, nearly quadrate; bearing small, blunt process along the outer margin. Second segment with distinct, posteriorly directed hook along the outer margin. Syncoxa of maxilla with 3 endites. P1 with 2-segmented exopod and endopod. Swimming legs P2-P4 with 3-segmented exopods and 2-segmented endopods; without sexual dimorphism except for a curved, stronger outer spine on exp-2 of the male P3. Chaetotaxy of the ultimate exopodal segments of P2-P4: 122, 222 and 222. Endopodal lobe of female P5 reaching to middle of exopod, bearing 4 setae. Exopod of female P5 ovate, bearing 5 setae. Male P5 baseoendopod obsolete, without endopodal seta; exopod small, bearing 3 setae.

Type species. Apistophonte wasiniensis gen. n. sp. n., monotypy.

Etymology. The generic name is a conjunction of apistos (Greek meaning treacherous, perfidious) and the suffix -phonte, and refers to the superficial and misleading resemblance of the genus to Propephonte gen. n. (gender feminine).

The above diagnosis coincides with that of its only known and type species, and must, therefore, be considered tentative. A differential diagnosis is presented in the discussion.

\section{Apistophonte wasiniensis Gheerardyn and Fiers gen. n., sp. n.}

Type locality.-Western Indian Ocean, Kenyan coast, Wasini Island ( $\left.4^{\circ} 40^{\prime} \mathrm{S}, 39^{\circ} 23^{\prime} \mathrm{E}\right)$, red (terrigenous?) sediment, water depth 3-4 m.

Material.- (a) From type locality: holotype $q$ dissected on 4 slides (COP4727a-d); allotype $\sigma^{x}$ dissected on 3 slides (COP4728a-c); paratypes are $2+\%$ and $1 \sigma^{x}$ dissected on slides (COP4729-COP4731) and 6 \% $\%$ and $40^{\pi} 0^{\pi}$ preserved in 75\% alcohol (COP4732); collected 28 February 2002 by M. Raes.

(b) Western Indian Ocean, Kenyan coast, Kisite Island (4'43'S, 39 $\left.22^{\prime} \mathrm{E}\right)$, coral sand, water depth 3-6 m. : paratypes, 3 우 preserved in 75\% alcohol (COP4733); collected 28 February 2002 by M. Raes.

Etymology.-The specific name wasiniensis refers to the type locality of this species. 
Total body length 299-406 $\mu \mathrm{m}(\mathrm{n}=9$; average $=361 \mu \mathrm{m}$; measured from anterior margin of rostrum to posterior margin of caudal rami). Largest width measured at posterior margin of cephalothorax: $88 \mu \mathrm{m}$.

Rostrum (Fig. 2A) large with straight lateral margins; broad triangular; fused to cephalothorax; with a pair of sensilla anteriorly; dorsal surface pitted.

Habitus (Fig. 1A-B). Body fusiform prehensile. Cephalothorax with parallel margins. Free prosomites slightly less wide as cephalothorax. Genital double-somite and following urosomite ventrolaterally expanded. Urosome gently tapering towards the anal somite. Second and third urosomite fused to form genital double-somite. Original division between first and second somite of genital double-somite is marked serrate dorsally.

Integument of the cephalothorax pitted; with symmetrical pattern of smooth areas; regularly ornamented with small sensilla. Surface of pleurotergites and dorsal surface of anal somite pitted entirely. Posterodorsal margin of cephalothorax smooth. Posterodorsal margin of the free somites serrate. Posterolateral angles of cephalothorax slightly extended. Posterodorsal margins of cephalothorax and free somites (except penultimate urosomite) bearing a number of small sensilla. Free prosomites and first urosomite additionally bearing 1 pair of sensilla dorsally. Anal operculum not protruding backwardly; flanked by 2 sensilla; with serrate margin.

Ventral surface (Fig. 4A) of genital double-somite smooth, except for some striae in anterior part; bearing spinular row laterally from P6 vestiges. Genital double-somite and following 2 somites bearing few spinules laterally. Ventral surface of fourth urosomite smooth; of fifth urosomite with some small spinules in posterior part; of anal somite pitted. Posteroventral margins of genital double-somite and following urosomites bearing row of slender to strong spinules.

Caudal rami (Fig. 4A, 4C) almost 1.5 times as long as wide; cylindrical with slightly convex inner margin; bearing spinules along the inner margin and several spinular rows on the ventral surface; with some small denticles and pits dorsally. Seta I, II and III inserted in distal fourth of outer margin. Seta I rudimentary. Seta IV and V not fused; seta IV pinnate, seta V naked. Seta VII inserted in the distal fourth. Antennule (Fig. 2A) 6-segmented; majority of setae long and slender. Segment 1 and 2 bearing few pits dorsally, ventral surface smooth; segment 3-6 smooth. Segment 1 short, slightly longer than wide; bearing small, blunt process along outer margin; with spinular row along inner margin. Segment 2 with distinct, posteriorly directed hook along outer margin. Armature formula: 1-[1], 2-[7 + 1 pinnate], 3-[7], 4-[1+(1+ae)], 5-[1], 6-[9+ acrothek]. Apical acrothek consisting of a small aesthetasc fused basally to 2 setae.

Antenna (Fig. 2F). Allobasis bearing 2 spinular rows; with 1 short, unipinnate abexopodal seta, inserted in distal third. Exopod 1-segmented and small, well developed; bearing 4 sub-equal bipinnate setae, the dorsal one being more slender and less dense pinnate. Endopod with 2 rows of spinules and 1 sub-apical frill; with following armature: 2 
spines (1 unipinnate) and slender seta subapically, 2 claw-like spines, 3 geniculate setae and small, slender seta apically.

Mandible (Fig. 2B). Biting edge formed by several blunt teeth and seta. Palp uniramous; endopod and exopod represented by 3 and 1 smooth seta(e), respectively. Medial seta plumose.

Maxillule (Fig. 2G). Praecoxal arthrite bearing spinular row on posterior surface; with 5 setae/spines apically; with 1 small, obliquely positioned seta along the outer margin and 2 small setae along the inner margin. Coxal endite with 1 seta and 1 curved spine. Basal endite with 2 naked setae and 1 curved spine. Endopod obsolete, represented by 3 setae. Exopod 1-segmented with 2 apical setae.

Maxilla (Fig. 2H). Syncoxa with 3 endites; with 1 row of spinules along outer margin and 2 along inner margin. Praecoxal endite small, with 1 seta. Proximal coxal endite with 1 strong, pinnate spine and 2 slender, naked setae. Distal coxal endite with 1 strong, pinnate spine and 2 slender, naked setae. Allobasis drawn out into strong, slightly curved claw; bearing 2 setae. Endopod obsolete, represented by 2 naked setae.

Maxilliped (Fig. 2E). Syncoxa with 2 spinular rows; apically bearing pinnate seta and rudimentary seta next to it. Basis with some spinules along the slightly convex outer margin. Endopod claw-shaped, unarmed, with short, naked seta at base.

P1 (Fig. 3A). Coxa cylindrical with 1 inner and 2 outer spinular rows. Basis with 1 pinnate seta along outer margin; medial, unipinnate seta arising on anterior surface; spinules on anterior surface, along inner and outer margin. Exp-1 bearing 1 unipinnate outer seta, spinular row along the outer margin and a few spinules on the anterior surface; exp-2 bearing 3 naked outer setae and 2 geniculate apical setae, with a few spinules on the anterior surface. Enp-1 2.5 times as long as exp, with few spinules along the inner margin; enp-2 with 1 strong, smooth claw and 1 minute, naked accessory seta.

P2-P4 (Fig. 3B-D). Setal formulae in table 1. Exopods 3-segmented and endopods 2segmented. Prae-coxae small and triangular. Coxae and bases with spinules along the outer margin. Inner margin of basis in P2 and P3 with some slender long hairs. Outer margin of basis with short, pinnate (P2) or long, naked (P3-P4) seta. P2 endopod reaching to the proximal third of exp-3. P3 endopod reaching just beyond the middle of exp-2. P4 endopod slightly longer than exp-1. Segments of endopods and exopods with pattern of spinules as figured.

TABLE 1. Swimming leg setal formulae of Apistophonte wasiniensis gen. et sp. n. and Propephonte duangitensis gen. et sp. $\mathbf{n}$.

\begin{tabular}{lllllll}
\hline & P2 & & P3 & \multicolumn{2}{l}{ P4 } \\
& $\exp$ & end & exp & end & exp & enp \\
\hline Apistophonte wasiniensis & 0.1 .122 & 0.220 & 0.1 .222 & 0.220 & 0.1 .222 & 0.120 \\
Propephonte duangitensis & 0.1 .122 & 0.120 & 0.1 .222 & 0.120 & 0.1 .222 & $0.110\left(\odot^{\star} 0.010\right)$ \\
\hline
\end{tabular}



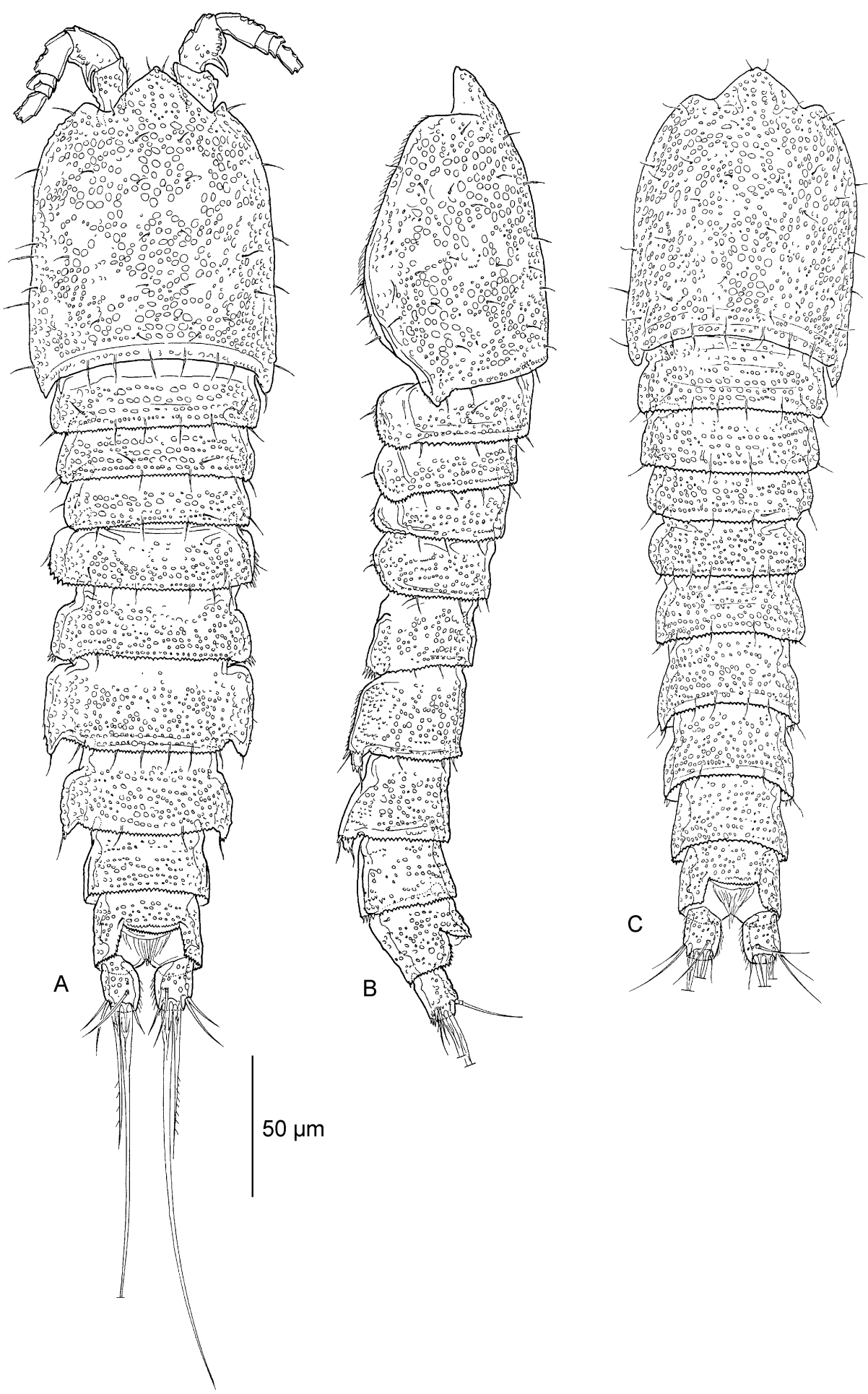

FIGURE 1. Apistophonte wasiniensis sp. n. (, COP 4727). A, habitus, dorsal; B, habitus, lateral. C (ox, COP 4728), habitus, dorsal. 


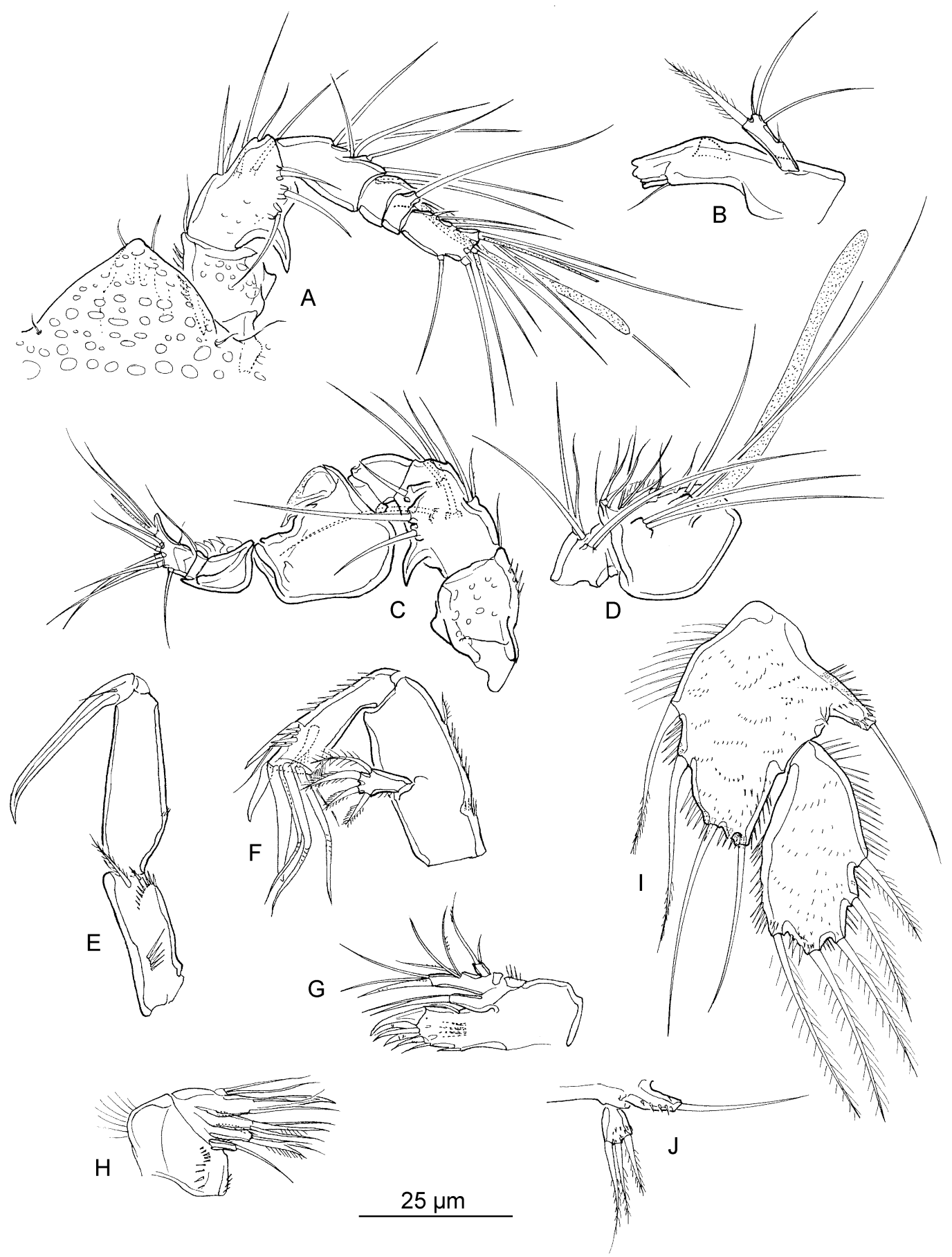

FIGURE 2. Apistophonte wasiniensis sp. n. A-B, E-I (ㅇ, COP 4727); C-D, J (ox, COP 4728). A, antennule and rostrum, dorsal; B, mandible; C, antennule (armature of segments 3-5 omitted), dorsal; D, antennule (segments 3-5), ventral; E, maxilliped; F, antenna; G, maxillule; H, maxilla; I, P5, anterior; J, P5, anterior. 


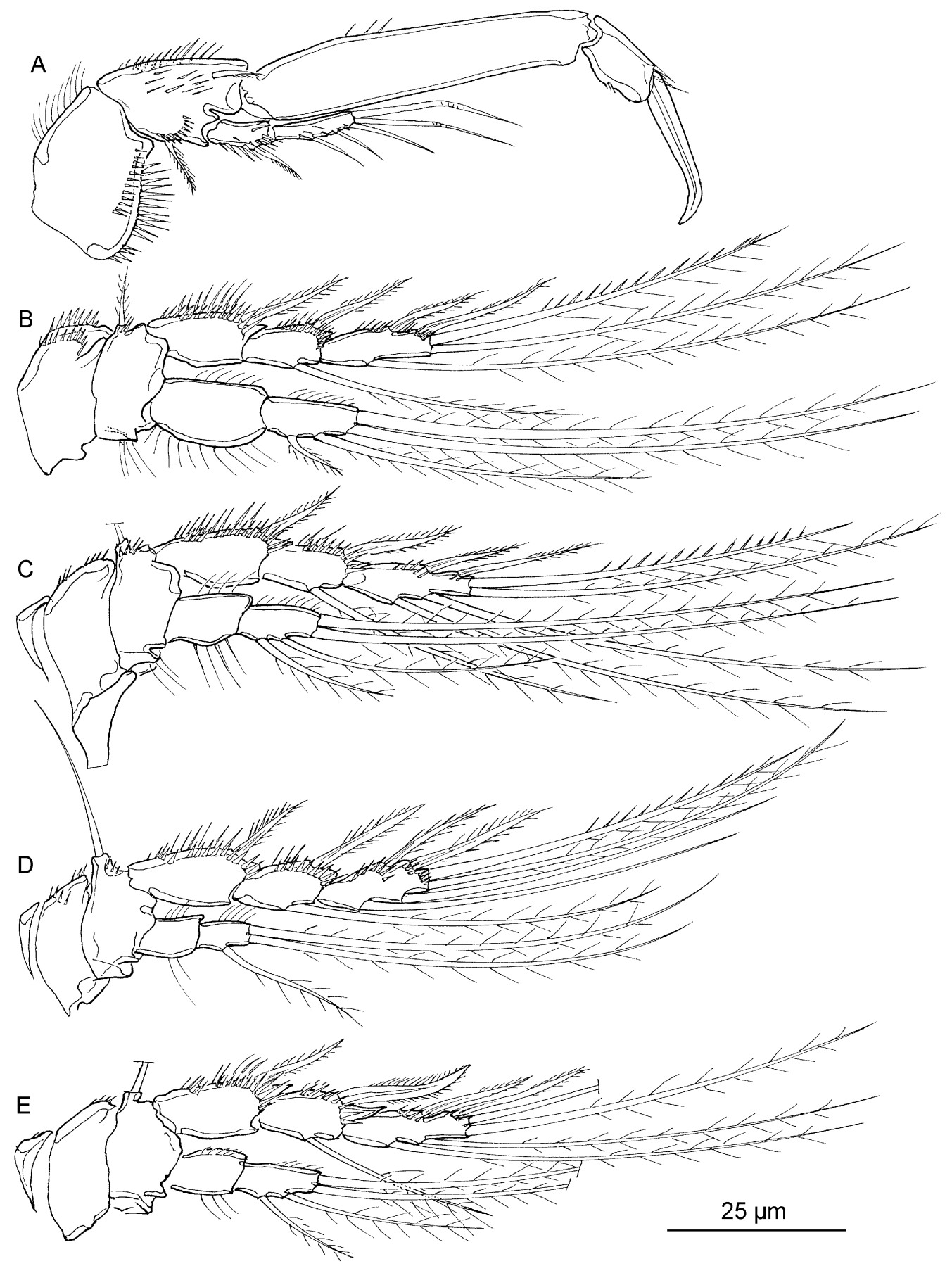

FIGURE 3. Apistophonte wasiniensis sp. n. ( $\left.{ }^{+}, \mathrm{COP} 4727\right)$. A, P1, anterior; B, P2, anterior; C, P3, anterior; D, P4, anterior. E ( $\sigma^{\star}$, COP 4728), P3, anterior. 

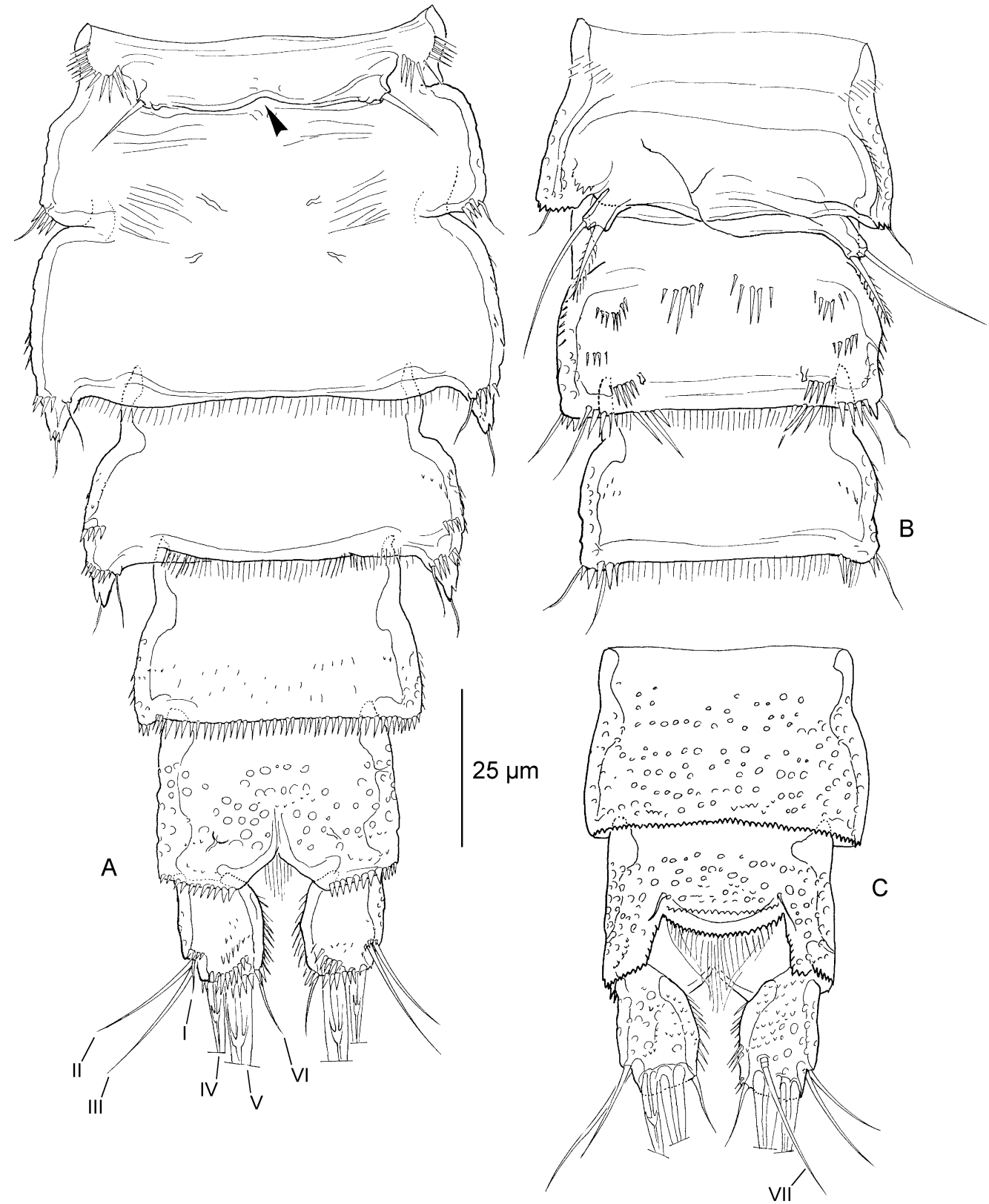

FIGURE 4. Apistophonte wasiniensis sp. n. A ( + , COP 4727), urosome (copulatory pore arrowed), ventral. B ( $\sigma^{x}$, COP 4728), second to fourth urosomite, ventral. C (ㅇ, COP 4727), anal somite and caudal rami, dorsal.

P5 (Fig. 2I) with separate exopod and baseoendopod; both covered anteriorly with few small spinules; the margins bearing strong and long spinules. Basal seta arising from a cylindrical setophore. Proximal setae of endopodal lobe bipinnate; sub-apical and apical seta naked. Baseoendopod reaching to middle of exopod. Exopod with ovate shape; about 
2 times as long as wide; bearing 5 plumose setae.

P6 vestiges (Fig. 4A) bearing 1 seta. Copulatory pore minute, situated in middle of anterior somite.

\section{Description of male}

Total body length $280-387 \mu \mathrm{m}(\mathrm{n}=6$; average $=326 \mu \mathrm{m}$; measured from anterior margin of rostrum to posterior margin of caudal rami). Largest width measured at posterior margin of cephalothorax: $78 \mu \mathrm{m}$.

Habitus (Fig. 1C) as in female; except for the fully separated second and third urosomite, and the lack of ventrolateral extensions in the second to fourth urosomites (Fig. 4B). Ventral surface of third urosomite bearing several short rows of long spinules. Posteroventral margin of third urosomite with slender hairs and some long spinules near the lateral sides.

Antennule (Fig. 2C-D) 8-segmented; sub-chirocer. Segment 1 and 2 as in female. Armature formula: 1-[1], 2-[8 + 1 pinnate], 3-[5 (?)], 4-[2], 5-[10 (?) + 1 pinnate $+(1+$ ae)], 6-[0], 7-[1], 8-[7 + acrothek]. Apical acrothek consisting of a small aesthetasc fused basally to 2 setae.

Antenna, mouthparts and P1 as in female.

Endopods of P2-P4 as in female. Exopods of P2 and P4 as in female; except that the inner seta on exp-2 is shorter than the corresponding seta in the female (reaching not far beyond the distal margin of exp-3). P3 exopod (Fig. 3E) as in female; except for a curved, stronger outer spine on exp-2, the distal outer corner of exp-2 being more strongly developed and the inner seta on exp-2 being shorter than the corresponding seta in the female (reaching not far beyond the distal margin of exp-3).

P5 (Fig. 2J). Endopodal lobe of P5 obsolete; without a seta. Exopod small; slightly longer than wide; bearing 3 plumose setae.

P6 vestiges (Fig. 4B) asymmetrical. One vestige functional; one vestige fused to somite. Both produced into a cylindrical process bearing 1 pinnate inner and 1 naked outer seta.

Variability.-Among the 12 females and 6 males studied, no variability in setal formulae was observed.

Known range.-To date, A. wasiniensis is only known from Wasini and Kisite Islands along the Kenyan coast.

\section{Family Laophontidae T. Scott, 1905}

Subfamily Laophontinae T. Scott, 1905 sensu Huys and Lee, 2000

\section{Genus Propephonte Gheerardyn and Fiers gen. n.}

Diagnosis. Laophontidae. Body fusiform prehensile, slightly depressed. Rostrum 
prominent. Integument of cephalothorax and somites pitted. Posterodorsal margin of prosomites, urosomites and anal operculum serrate. Ventral surface of third male urosomite with rows of large spinules. Caudal rami cylindrical without dorsal processes. Female antennule 6-segmented; first segment distinctly elongate, with a blunt process proximally on the dorsal surface and a distinct process along the outer margin; second segment with a large, posteriorly directed hook along the outer margin. Syncoxa of maxilla with 2 endites. P1 with a 2-segmented exopod. Swimming legs P2-P4 with 3-segmented exopods and 2-segmented endopods; without sexual dimorphism. Chaetotaxy of the ultimate exopodal segments of P2-P4: 122, 222 and 222. Endopodal lobe of female P5 reaching to middle of exopod, bearing 4 setae. Exopod of female P5 ovate, bearing 5 setae. Male P5 baseoendopod obsolete, with endopodal seta; exopod bearing 5 setae.

Type species.-Propephonte duangitensis gen. n. sp. n., monotypy.

Etymology.-The generic name is a conjunction of prope (Latin meaning close, almost) and the suffix -phonte, and refers to the close relationship of the genus with Peltidiphonte Gheerardyn and Fiers, 2006 (gender feminine).

The above diagnosis coincides with that of its only known and type species, and must, therefore, be considered tentative. A differential diagnosis is presented in the discussion.

\section{Propephonte duangitensis Gheerardyn and Fiers gen. n., sp. n.}

Type locality.-Western Pacific Ocean, Papua New Guinea, Madang Province, Hansa Bay (Duangit Reef) ( $\left.4^{\circ} 10^{\prime} \mathrm{S}, 144^{\circ} 53^{\prime} \mathrm{E}\right)$, coral sand and coral rubble from the east side, water depth 40-46 m.

Material.- - Holotype + dissected on 1 slide (COP1940); allotype $0^{x}$ dissected on 1 slide (COP1941); paratypes are $1 \%$ dissected on 3 slides (COP4726a-c) and $1 \sigma^{\pi}$ preserved in 75\% alcohol (COP1942); all collected 28 May 1979 by J. Pierret.

Etymology._The specific name duangitensis refers to the type locality of this species.

\section{Description of female}

Total body length 326-350 $\mu \mathrm{m}$ (measured from anterior margin of rostrum to posterior margin of caudal rami). Largest width measured at posterior margin of cephalothorax: 88 $\mu \mathrm{m}$.

Rostrum (Fig. 6E) strongly prominent and triangular; fused to cephalothorax; rather narrow, with slightly concave margins; tip small, slightly bifid; with pair of sensilla anteriorly; dorsal surface pitted.

Habitus (Fig. 5A-B). Body fusiform prehensile, slightly depressed. Cephalothorax with parallel margins, only tapering in anterior quarter. Free prosomites and first urosomite as wide as cephalothorax; second to fourth urosomites expanded ventrolaterally. Urosome gently tapering towards the anal somite. Posterolateral angles of cephalothorax lobate. Pleural areas of free prosomites well developed and rounded, bearing spinules along margin. Second and third urosomite fused to form genital double-somite. Genital double- 
somite with transverse serrate surface ridge dorsally and laterally, indicating original segmentation; fused ventrally.

Integument of cephalothorax pitted; regularly ornamented with small sensilla. Pleurotergites of prosomites and urosomites, and dorsal surface of anal somite and caudal rami entirely pitted. Rows of closely arranged pits transforming into rows of small denticles. Posterodorsal margin of cephalothorax smooth; of the free somites serrate. Posterodorsal margins of cephalothorax and free somites (except penultimate urosomite) bearing a number of small sensilla. Anal operculum well developed and slightly protruding backwardly; flanked by 2 sensilla; with serrate margin.

Ventral surface (Fig. 9A) of the genital double-somite striated anteriorly, smooth posteriorly. Ventral surface of following 2 urosomites smooth; of anal somite pitted. Posteroventral margins of genital double-somite and following urosomites bearing a row of spinules.

Caudal rami (9A-B) almost twice as long as wide; cylindrical; surface of the caudal rami without processes. Ventral surface and outer margin of the caudal rami spinulose. Inner margin slightly tapering towards the distal margin and bearing strong spinules. Seta I, II and III inserted in distal third of outer margin. Seta IV and V not fused. Seta VII inserted in the distal third.

Antennule (Fig. 6A) 6-segmented; majority of setae long and slender. Segment 1-3 pitted dorsally, smooth ventrally. Segment 4-6 smooth. Segment 1 elongate, almost 2.5 times as long as wide; dorsally with blunt process on the proximal half; outer margin bears blunt thorn proximally. Segment 2 with large, posteriorly directed hook along outer margin. Inner margin of first to third segment and outer margin of third to sixth segment with spinules. Armature formula: 1-[1 pinnate], 2-[7+1 pinnate], 3-[7], 4-[1+(1+ae)], 5-[1], 6-[9 + acrothek]. Apical acrothek consisting of a small aesthetasc fused basally to 2 setae.

Antenna (Fig. 6B). Allobasis with 1 short, unipinnate abexopodal seta, inserted in distal half. Exopod 1-segmented and small, but well developed; bearing 3 sub-equal setae apically, and 1 bipinnate, slender and slightly longer seta sub-apically. Endopod with 2 rows of spinules and 2 sub-apical frills; with following armature: subapically 2 spines (one is unipinnate) and a small, slender seta, apically 2 claw-like spines, 3 geniculate setae (the outermost pinnate) and 1 slender seta.

Mandible (Fig. 6F). Biting edge formed by several blunt teeth and a seta. Palp uniramous; endopod and exopod represented by 3 and 1 smooth seta(e), respectively. Medial seta plumose.

Maxillule (Fig. 6G). Praecoxal arthrite bearing a spinular row on the posterior surface; apically with 6 setae/spines; with 1 small, obliquely positioned seta along the outer and 2 slender setae along the inner margin. Coxal endite with 1 seta and 1 curved spine. Basal endite with 2 setae and 1 curved spine. Endopod obsolete, represented by 3 setae. Exopod 1-segmented with 2 apical setae. 
Maxilla (Fig. 6H). Syncoxa with 2 endites; with a spinular row along the inner and along the outer margin. Praecoxal endite absent. Proximal coxal endite with 1 strong, pinnate spine and 2 slender, naked setae. Distal coxal endite with 1 curved spine and 1 slender seta. Allobasis drawn out into strong, slightly curved, distally pinnate claw; bearing 2 setae. Endopod obsolete, represented by 2 setae (one of which is very short).

Maxilliped (Fig. 6I). Syncoxa with spinular row along the outer margin and some spinules proximally; apically bearing pinnate seta and small seta next to it. Basis with slightly convex outer margin. Endopod clawshaped, unarmed, with short, naked seta at base.
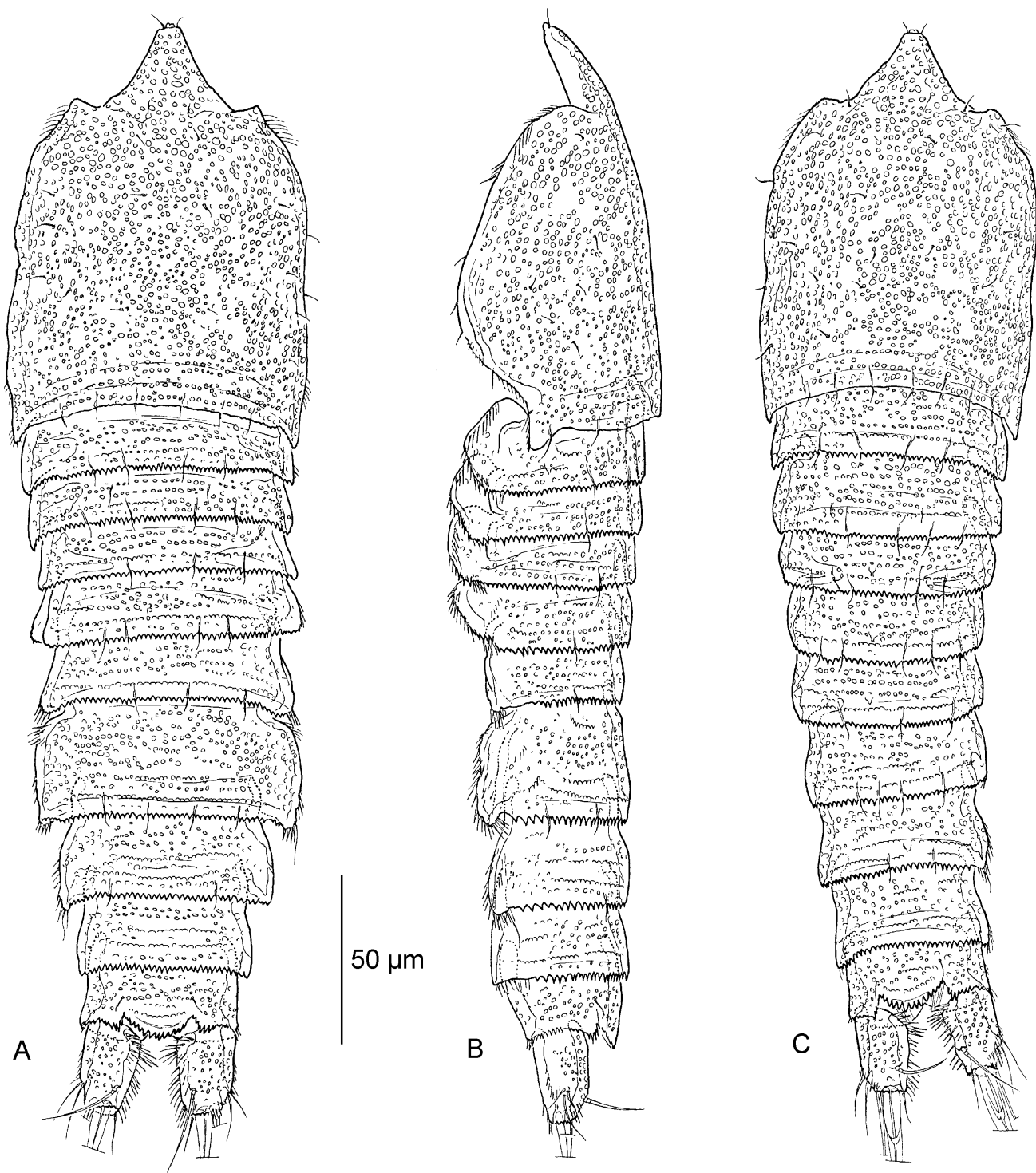

FIGURE 5. Propephonte duangitensis sp. n. ( ${ }^{+}$, COP 4726). A, habitus, dorsal; B, habitus, lateral. C ( $0^{x}$, COP 1942), habitus, dorsal. 


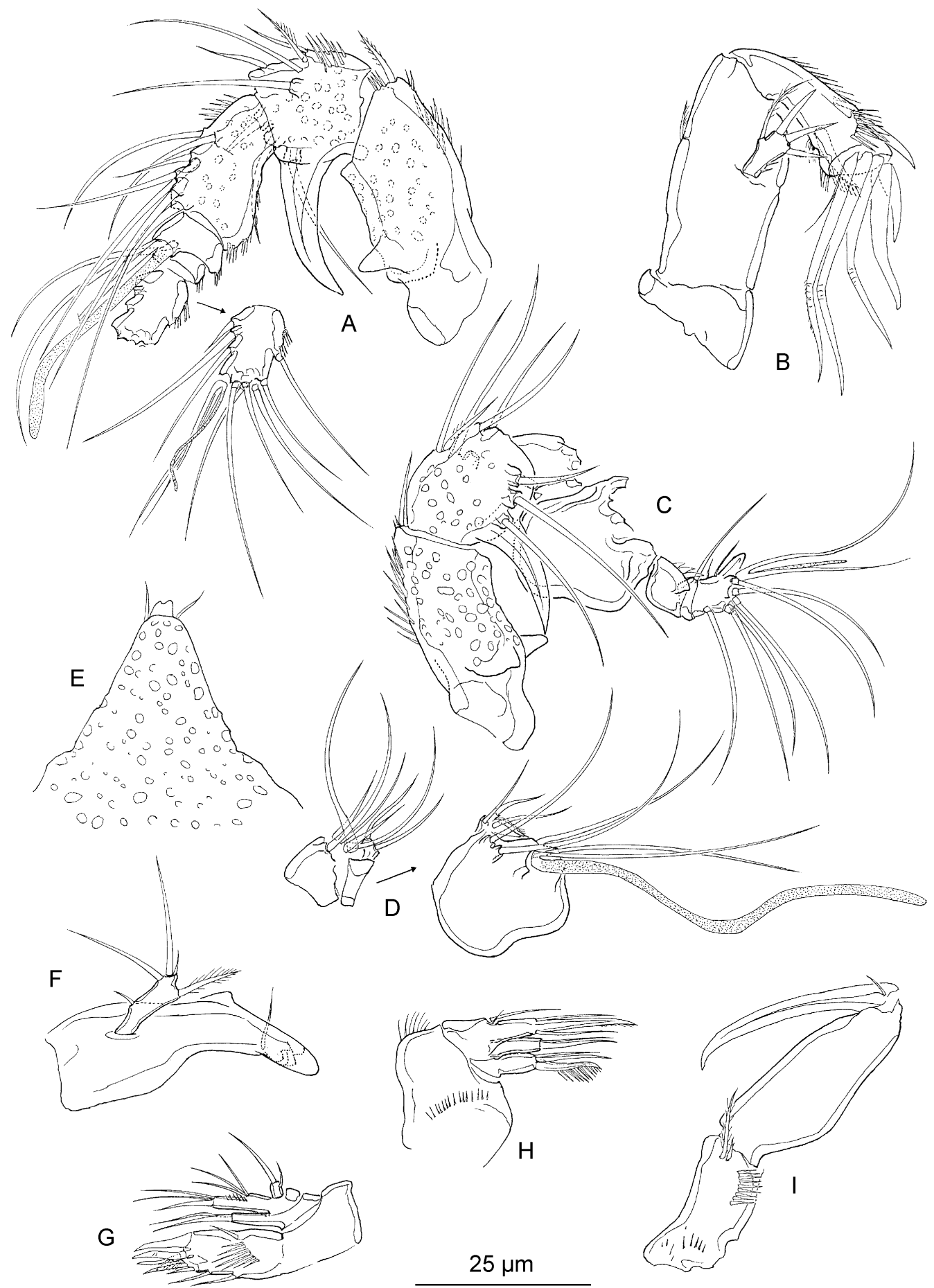

FIGURE 6. Propephonte duangitensis sp. n. A-B, E-I (ㅇ, COP 1940); C-D (o, COP1941). A, antennule, ventral; B, antenna; C, antennule (armature of segments 3-5 omitted), dorsal; D, antennule (segments 3-5), ventral; E, rostrum; F, mandible; G, maxillule; H, maxilla; I, maxilliped. 


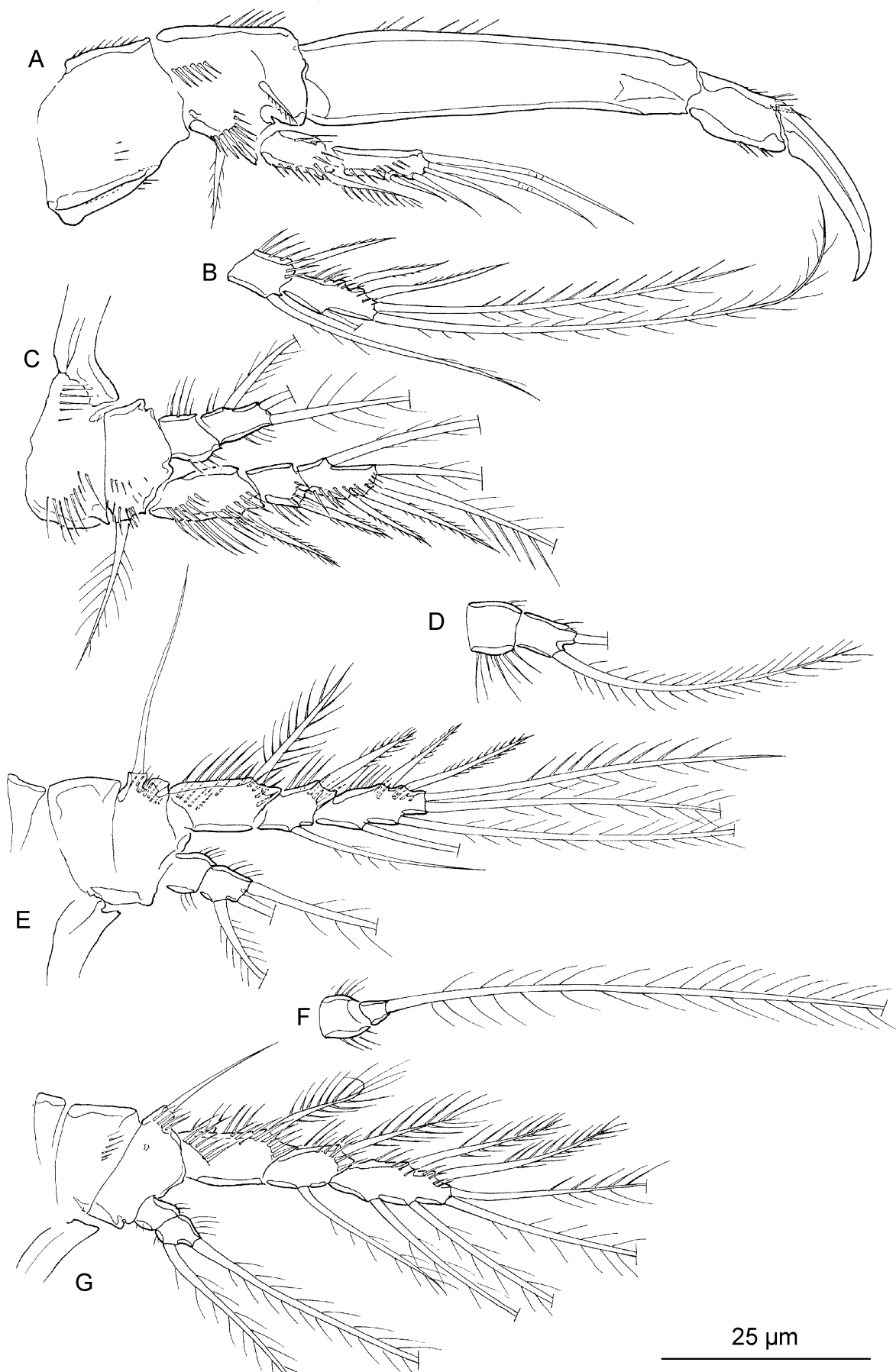

FIGURE 7. Propephonte duangitensis sp. n. ( + , COP 1940). A, P1, anterior; B, left P2 exp-2 and exp-3, anterior; C, right $\mathrm{P}$ 2, anterior; D, left P2 enp, anterior; E, right P3, posterior; F, left P3 enp, posterior; $\mathrm{G}$, left $\mathrm{P} 4$, anterior. 


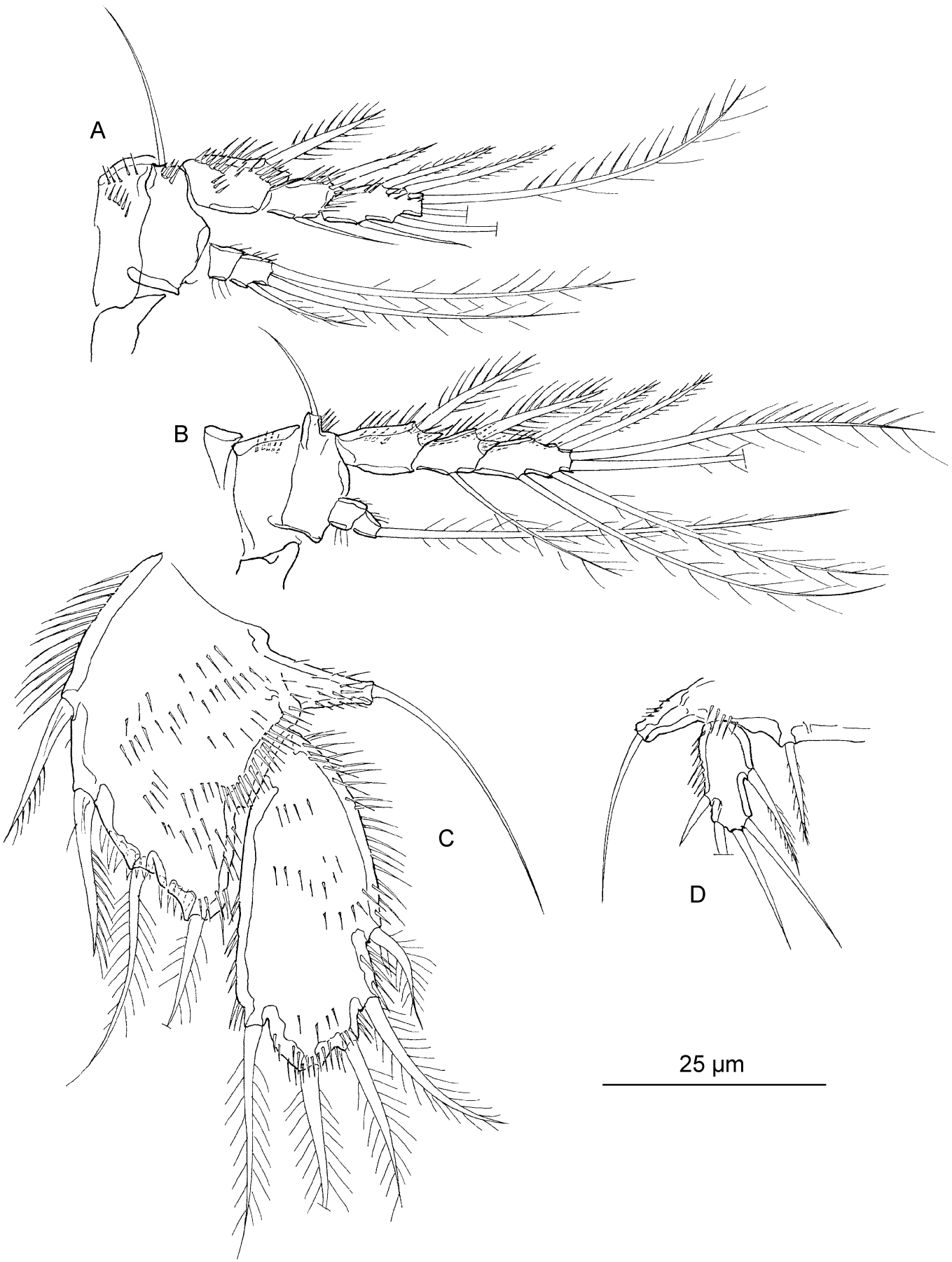

FIGURE 8. Propephonte duangitensis sp. n. A-B, D (ox, COP 1941); C (, COP 1940). A, P3, anterior; $\mathrm{B}, \mathrm{P} 4$, posterior; C, $\mathrm{P}$, anterior; $\mathrm{D}, \mathrm{P} 5$, anterior.

P1 (Fig. 7A). Coxa and basis cylindrical, each about as long as broad; with several spinular rows. Basis with slender, plumose outer seta; inner unipinnate seta arising on 
anterior surface. Exopod 2-segmented, outer margins and anterior surfaces with spinules. Exp-1 with a strongly armed outer spine; exp-2 with 3 naked outer setae and 2 geniculate apical setae. Enp-1 about 2.5 times as long as exp; enp- 2 with a strong, smooth claw and 1 minute, naked accessory seta.

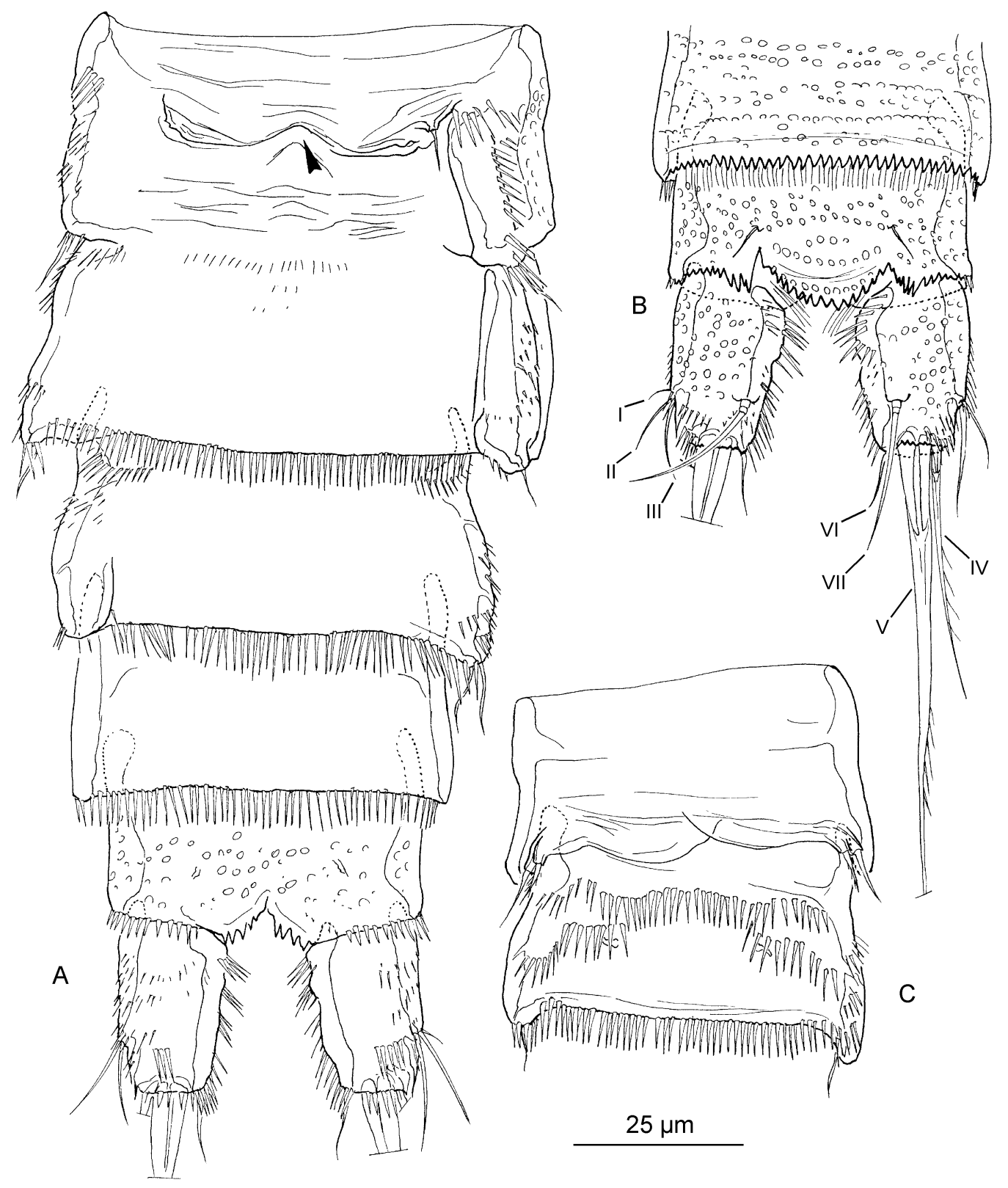

FIGURE 9. Propephonte duangitensis sp. n. (ㅇ, COP 4726). A, urosome (copulatory pore arrowed), ventral; B, anal somite and caudal rami, dorsal. C (o*, COP 1941), second and third urosomite, ventral. 
P2-P4 (Fig. 7B-7G). Setal formulae in table 1. Exopods 3-segmented and endopods 2segmented. Prae-coxae small and triangular; devoid of integumental structures. Coxae and bases with spinules along the outer margin. Outer margin of basis with long, plumose (P2) or long, naked (P3-P4) seta. Proportional lengths of the endopods rather short; reaching to middle of exp-2 in P2, to the distal margin of exp-1 in P3 and to middle of exp-1 in P4. Outer spine of exp-1 of P3 and outer exopodal spines of P4 ornamented with slender, long spinules. Segments of endopods and exopods with pattern of spinules as figured.

P5 (Fig. 8C) with separate exopod and baseoendopod; the margins bearing long, slender spinules or stout, short spinules. Anterior surface furnished with rows of spinules. Proximal setae of endopodal lobe unipinnate; sub-apical and apical seta plumose. Baseoendopod reaching to middle of exopod. Exopod ovate shape; about 2 times as long as wide; bearing 5 plumose setae distally.

P6 vestiges (Fig. 9A) each bearing 1 small, naked seta. Copulatory pore minute, situated in middle of anterior somite.

\section{Description of male}

Total body length 309-350 $\mu \mathrm{m}$ (measured from anterior margin of rostrum to posterior margin of caudal rami). Largest width measured at posterior margin of cephalothorax: 80 $\mu \mathrm{m}$.

Habitus (Fig. 5C). More slender than female; especially with respect to the urosome. Second and third urosomite fully separated. Ventrolateral extensions of second to fourth urosomite are absent. Ventral surface of third urosomite with 2 rows of long spinules; anterior one along the entire surface, posterior one with a large gap in the middle (Fig. 9C).

Antennule (Fig. 6C-D) 8-segmented; sub-chirocer. Segment 1 and 2 as in female. Armature formula: 1-[1], 2-[8 + 1 pinnate], 3-[6], 4-[2], 5-[9 (?) + (1 + ae)], 6-[0], 7-[1], 8[8+ acrothek]. Apical acrothek consisting of a small aesthetasc fused basally to 2 setae.

Antenna, mouthparts and $\mathrm{P} 1$ as in female.

Swimming legs P2-P4 as in female (Fig. 8A-B), except enp-2 of P4 has lost the inner seta.

P5 (Fig. 8D) pair of legs medially fused. Endopodal lobe of P5 obsolete; bearing 1 pinnate seta. Exopodite oblong; bearing 5 setae and a row of spinules along the outer margin.

P6 vestiges (Fig. 9C) asymmetrical; 1 vestige functional; 1 vestige fused to somite; outer distal corner with 1 pinnate inner and 1 naked outer seta, each on small pedestal.

Variability.-The female holotype has a left P2 enp (Fig. 7D) with only one apical seta, a right P2 exp-2 (Fig. 7C) without an inner seta and a left P3 enp (Fig. 7F) with a very small second segment, bearing only one seta. The allotype bears only two setae on the right endopod of $\mathrm{P} 3$, which contrasts with the other paratypes and the left endopod of the same specimen.

Known range.-To date, $P$. duangitensis is known from the type locality only. 
Apistophonte gen. n. and Propephonte gen. n. are both placed in the family Laophontidae and more specifically in the subfamily Laophontinae T. Scott, 1905 sensu Huys and Lee, 2000 based on the following synapomorphies as defined by Huys and Lee (2000): male antennule with up to three segments distal to geniculation, proximal aesthetasc fused to one seta, mandible uniramous, maxilliped with maximum two setae on syncoxa, P1 enp-1 without inner seta, P2 enp-2 without outer spine, proximal outer setae of female P5 exopod with distinctly separated insertion sites and absence of cup-shaped transformed pores on legs or somites. Both genera differ from most other laophontid genera in the absence of sexual dimorphism in the P2-P4 endopods. In the superfamily of Laophontoidea T. Scott, a particularly robust character is the presence of sexual dimorphism in the P3 endopod (Huys 1990). The male apophysis of the Laophontoidea can be unequivocally defined as the homologue of the female outer spine on the distal endopodal segment of P3. As a consequence of the loss of this outer spine, a sexually dimorphic apophysis on the male P3 endopod is absent, as stated by Huys (1990). This loss has occurred independently in several lineages in the Laophontidae as shown by e.g. Echinolaophonte tetracheir Mielke, 1981, Lipomelum Fiers, 1986, Loureirophonte Jakobi, 1953, Paralaophonte aenigmaticum Wells, Hicks and Coull, 1982 and Peltidiphonte Gheerardyn and Fiers, 2006.

At first sight, Apistophonte wasiniensis sp. n. and Propephonte duangitensis sp. n. resemble each other very closely because of their comparable habitus, pitted integument, absence of sexual dimorphism in the P2-P4 endopods, chaetotaxy of the swimming legs and similar female P5. Closer examination of A1, mouthparts, male P5 and proportions of the endopods of the swimming legs nevertheless reveals that these two new species are not congeneric and furthermore, cannot be included in any of the known genera.

The first antennular segment in Propephonte gen. n. is elongate (almost 2.5 times as long as wide), and bears a distinct process proximally on the dorsal surface and a blunt thorn along the outer margin. This particular structure of the first antennular segment indicates a close relationship with the genus Peltidiphonte. Furthermore, the fifth pereiopods of male and female of both genera are similar in shape and setation, up to the shape of the setae. Propephonte gen. n. and Peltidiphonte have both lost the praecoxal endite on the maxilla and the outer spine on the P3 endopod. Based on these shared characteristics, we assume that Propephonte gen. n. and Peltidiphonte belong to the same lineage in which Peltidiphonte became adapted to an epibenthic life style by becoming dorsoventrally flattened. The laterally extended pleurotergites of the prosomites and the broad and wing-like urosomites are a distinct apomorphy for the latter genus. Propephonte gen. n. shows a typical fusiform prehensile, but slightly depressed, habitus. As Peltidiphonte has a three-segmented P1 exopod and three outer spines on the ultimate exopodal segments of the swimming legs, the two-segmented P1 exopod and the reduced chaetotaxy of the last exopodal segments are apomorphies supporting the establishment of Propephonte gen. n. The male of Propephonte duangitensis sp. n. furthermore has lost the 
inner seta on the second endopodal segment of P4.

As shown by the structure of A1, maxilla and male and female P5, it is plausible that Indolaophonte Cottarelli, Saporito and Puccetti, 1986 and Langia Wells and Rao, 1987 are more derived genera within this lineage, wherein the setation and segmentation of the swimming legs became more reduced as an adaptation to the interstitial life style. The distal process on the caudal ramus (being homologous to a posterior outgrowth of the outer distal corner) is a distinct synapomorphy for these two genera. The first antennular segment in both genera is elongate and bears a distinct process along the outer margin. However, a process on the dorsal surface is not drawn nor mentioned in the text of the original descriptions of the two species of Indolaophonte (Cottarelli et al. 1986; Cottarelli and Puccetti 1988). An as yet undescribed species of Indolaophonte conversely shows the presence of this dorsal process (personal observation by F.F.). The detailed structure of the antennule in the monospecific genus Langia is rather unclear in the drawing by Wells and Rao (1987). The outer process on the first segment seems to be confluent with a dorsal elevation. In a redescription of Langia maculata Wells and Rao, 1987 by Mielke (1997), a dorsal process also appears to be absent. However, additional material from the northern coast of Papua New Guinea and the eastern coast of Bali clearly shows the presence of a dorsal process on the first antennular segment of this species (personal observation by F.F.).

It is worth mentioning that Propephonte duangitensis sp. n. was encountered in exactly the same sample as Peltidiphonte furcata Gheerardyn and Fiers, 2006 illustrating both species occur in the same type of habitat.

Contrary to the above-mentioned genera, the first antennular segment in Apistophonte gen. $\mathbf{n}$. is nearly quadrate (only slightly longer than wide) and only bears a small process along the outer margin. Other characteristics, such as the proportional size of the endopods (being distinctly longer than the respective ones in Propephonte gen. n. and Peltidiphonte) and the presence of a praecoxal endite on the maxilla, also show that Apistophonte wasiniensis gen. n. et sp. n. cannot be included in Propephonte gen. n. Although the female P5 is similar in shape and setation to the condition in Propephonte and Peltidiphonte, the shapes of the endopodal setae are however clearly different. In Apistophonte, the endopodal part of the female P5 bears two inner bipinnate, slender setae, and a sub-apical and apical naked seta. In Propephonte and all eight species of Peltidiphonte, the two inner elements are stout and unipinnate, while the sub-apical and apical seta are plumose. It is supposed that Apistophonte gen. n. branched off from a different stock than the lineage grouping Propephonte gen. n. and Peltidiphonte. As a consequence, the two-segmented P1 exopod and the reduced chaetotaxy of the last exopodal segments in Apistophonte gen. n. and Propephonte gen. n. have to be considered a result of convergence. Apistophonte gen. $\mathbf{n}$. is distinguished from the other genera of the family by the following combination of character states: the absence of sexual dimorphism in the endopods of the swimming legs, the strongly reduced male P5 (having lost the 
endopodal seta and bearing only three setae on the small exopod), the presence of a curved, stronger outer spine on exp-2 of the male P3 and the loss of the outer spine on the endopodite of P3. In our opinion, these features seem to be sufficient to justify the institution of the new genus.

The loss of the outer spine on the second endopodal segment of P3 could be a synapomorphy grouping Apistophonte gen. n., Propephonte gen. n. and Peltidiphonte. The absence of sexual dimorphism in the P2-P4 endopods however is not unique within the Laophontidae, as it has been lost several times. Therefore, it is difficult to elucidate the possible relationships of Apistophonte gen. n. with other genera of the family.

\section{Acknowledgements}

The first and last author acknowledge grants, as aspirant and postdoctoral fellow respectively, from the Fund for Scientific Research (FWO-Flanders, Belgium). The sampling campaign in Kenya was organised in the frame of the research project G.0199.03 'A comparative study of the meio-epifauna associated with tropical and cold-water coral reefs' sponsored by the same Fund for Scientific Research. Dr. G. Walker-Smith and two anonymous reviewers are kindly thanked for checking our manuscript.

\section{References}

Cottarelli, V., Saporito, P.E. \& Puccetti, A.C. (1986) Indolaophonte ramai n. gen. n. sp. (Crustacea, Copepoda, Harpacticoida) di acque interstiziali litorali dell'isola di Bali (Indonesia). Bollettino del Museo civico di storia naturale di Verona, 12, 273-281.

Cottarelli, V. \& Puccetti, A.C. (1988) Indolaophonte gemmarum n. sp. from interstitial littoral waters of Sri-Lanka (Crustacea, Copepoda, Harpacticoida). Fragmenta Entomologica, Roma, $20(2), 129-136$.

Fiers, F. (1986) Harpacticoid copepods from the West Indian Islands: Laophontidae (Copepoda, Harpacticoida). Bijdragen tot de Dierkunde, 56(1), 132-164.

Fiers, F. (1988) Taxonomie, Fylogenie en Zoogeografie van de Laophontidae (Copepoda, Harpacticoida), Vols. I, II. Ph.D. dissertation, Ghent University, Ghent, 1148 pp.

Gheerardyn, H., Fiers, F., Vincx, M. \& De Troch, M. (2006) Peltidiphonte gen. n., a new taxon of Laophontidae (Copepoda: Harpacticoida) from coral substrates of the Indo-West Pacific Ocean. Hydrobiologia, 553, 171-199.

Gheerardyn, H., Fiers, F., Vincx, M. \& De Troch, M. (in press) Paralaophonte harpagone sp. n. (Copepoda: Harpacticoida), a laophontid with an extremely specialised maxilliped. Organisms, Diversity and Evolution.

Huys, R. (1990) Amsterdam Expeditions to the West Indian Islands, Report 64. A new family of harpacticoid copepods and an analysis of the phylogenetic relationships within the Laophontoidea T. Scott. Bijdragen tot de Dierkunde, 60(2), 79-120.

Huys, R., Gee, J.M., Moore, C.G. \& Hamond, R. (1996) Marine and brackish water harpacticoid copepods. Part 1. Synopses of the British Fauna (New Series), 51. Field Studies Council, Shrewsbury. viii + 352 pp. 
Huys, R. \& Lee, W. (2000) Basal resolution of laophontid phylogeny and the paraphyly of Esola Edwards. Bulletin of the Natural History Museum London, Zoology Series, 66, 49-107.

Jakobi, H. (1953) Novos Laophontidae (Copepoda Crustacea) da costa Brasileira. Dusenia, 4(1), 47-60.

Mielke, W. (1981) Interstitielle Fauna von Galapagos. XXVIII. Laophontinae (Laophontidae), Ancorabolidae (Harpacticoida). Mikrofauna Meeresboden, 84, 1-106.

Mielke, W. (1997) On a small collection of Laophontidae (Copepoda) from Sulawesi, Indonesia. Microfauna Marina, 11, 223-250.

Wells, J.B.J., Hicks, G.R.F. \& Coull, B.C. (1982) Common harpacticoid copepods from New Zealand harbours and estuaries. New Zealand Journal of Zoology, 9, 151-184.

Wells, J.B.J. \& Rao, G.C. (1987) Littoral Harpacticoida (Crustacea: Copepoda) from Andaman and Nicobar Islands. Memoirs of the Zoological Survey of India, 16 (4), 1-385. 